\title{
Mushrooms as Natural Antimicrobial Agents
}

\author{
Celal BAL* \\ Gaziantep University, Turkey
}

*Corresponding author: Celal BAL, Gaziantep University, Turkey.

Received Date: October 17, 2019

Published Date: October 29, 2019

\begin{abstract}
In this study, nutritional and antimicrobial properties of mushrooms, which are important natural materials, are briefly mentioned. In this context, antimicrobial potential of mushrooms was emphasized.
\end{abstract}

\section{Introduction}

It is estimated that there are around 140,000 species of mushroom on earth, but so far only $10 \%$ (about 14,000) have been named and this number is increasing steadily [1]. Mushrooms are one of the oldest food sources in human history. Mushrooms have been regarded as important natural materials by many civilizations because of their taste, nutrient content and medicinal properties. The ancient Romans called "the food of the gods", the first Egyptians called "the gifts of the god of Osiris", and the Chinese called "the elixir of life". About 1000 fungus species are classified as edible in the world. Mushrooms are rich in minerals and contain many essential amino acids and contain vitamin B-rich proteins. In addition to its nutritional properties, many mushroom species have medicinal properties. Studies on mushrooms, which have an important place in terms of pharmacy, and which are thought to be around 140.000, are still at very low levels today [2,3]. Previously, mushrooms have been reported to have antimicrobial, antioxidant, antitumor, anti-inflammatory, larvicidal activity, cytotoxic activity, radionuclide activity, anticancer, anti-hyperglycaemic and immunomodulating properties [4-17].

Many antimicrobial drugs are used in the treatment of microorganisms. Although antimicrobial drugs used today are solutions for humans, they may be insufficient against microorganisms. Microorganisms that have become resistant to antimicrobial drugs remain an important problem that is difficult to solve in clinical practice. If the antimicrobial agent used in the treatment of a resistant microorganism is incorrectly selected, the treatment may fail. It can also cause a worse prognosis than a worse one. In addition, in cases where multidrug-resistant organisms are widely spread, there may be a very limited choice of agents for antimicrobial therapy. Today, very few new antimicrobial agents are used in the pharmaceutical market. In this context, determination of new antimicrobial agents is very important. Mushrooms are quite important natural sources used in alternative medicine. Today, in parallel with the increase in the number of diseases, alternative medicine tendency is gradually increasing due to insufficiency of synthetic medicines in these disadvantages. As an alternative to synthetic drugs, many natural resources such as plants, animals and mushrooms are used [18]. Mushrooms have been reported to have antimicrobial effects against different microorganisms in many studies.

In previous studies, ethanol extracts of Leucoagaricus leucothites (Vittad.) Wasser and Laetiporus sulphureus (Bull.) Murrill were reported to be effective against Pseudomonas aeruginosa, Escherichia coli, Enterococcus faecalis, Staphylococcus aureus, Candida tropicalis and Candida albicans [19-20]. Ethanol, methanol and dichloromethane extracts of Lentinus tigrinus (Bull.) Fr. were reported to be effective against $S$. aureus, S. aureus MRSA, E. faecalis, E. coli, P. aeruginosa, Acinetobacter baumannii, C. albicans, C. krusei and C. glabrata [21]. Methanol and dichloromethane extracts of Ganoderma lucidum (Curtis) P. Karst. were reported to be effective against $S$. aureus, S. aureus MRSA, E. faecalis, E. coli, P. aeruginosa, Acinetobacter baumannii, C. albicans, C. krusei and C. glabrata [22]. The extracts of acetone and methanol of Boletus 
aestivalis (Paulet) Fr., Boletus edulis Bull. and Leccinum carpini (R. Schulz) M.M. Moser ex D.A. Reid were reported to be effective against S. aureus, E. coli, Klebsiella pneumoniae, P. aeruginosa, E. faecalis, Aspergillus flavus, A. fumigatus, C. albicans, Paecilomyces variotii and Penicillium purpurescens [23]. Methanol extracts of Lycoperdon perlatum Pers., Cantharellus cibarius Fr., Clavaria vermicularis Sw., Ramaria formosa (Pers.) Quél., Marasmius oreades (Bolton) Fr., Pleurotus pulmonarius (Fr.) Quél. were reported to be effective against $S$. aureus, Bacillus subtilis, E. coli, P. aeruginosa and C. albicans [24]. Methanol extracts of Auricularia polytricha (Mont.) Sacc., Corilopsis occidentalis, Daldinia concentrica (Bolton) Ces. \& De Not., Daedalea elegans Spreng. and Tricholoma lobayense R. Heim were reported to be effective against B. cereus, E. coli, $K$. pneumoniae, A. niger, A. flavus, C. albicans and Microsporum boulardii [25]. Osmoporus odoratus (Wulfen) Singer were reported to be effective against petroleum ether, chloroform, acetone and water extracts against $S$. aureus, Streptococcus pyogenes, B. subtilis, E. coli and P. aeruginosa [26]. Methanol extracts of Pleurotus ostreatus (Jacq.) P. Kumm. were reported to be effective against $S$. aureus, E. coli, P. aeruginosa, E. faecalis, A. haemolyticus, K. pneumoniae, $S$. typhimirium and C. albicans [27].

\section{Conclussion}

As a result, different mushroom species have many medicinal properties as well as edible properties. Mushrooms attract attention with their antimicrobial properties. In this study antimicrobial properties of some mushrooms are given. In addition, antimicrobial properties of many different mushroom species are mentioned in the literature. In this context, mushrooms are very important natural materials with their antimicrobial properties as well as their rich nutritional content.

\section{Acknowledgement}

None.

\section{Conflict of Interests}

No conflict of interest.

\section{References}

1. Bal C, Akgul H, Sevindik M, Akata I, Yumrutas O (2017) Determination of The Anti- Oxidative Activities of Six Mushrooms. Fresenius Environmental Bulletin 26(10): 6246-6252.

2. Reis FS, Heleno SA, Barros L, Sousa MJ, Martins A, et al. (2011) Toward the antioxidant and chemical characterization of mycorrhizal mushrooms from Northeast Portugal J Food Sci 76(6): C824-C830.

3. Soto F, Velázquez MO, Santiago WG, Pérez Ovando EC (2017) Traditional Processing and Preservation of Wild Edible Mushrooms in Mexico. Ann Food Process Preserv 2(1): 1013.

4. Yilmaz A, Yıldız S, Çelik A, Çevik U (2016) Determination of Heavy Metal and Radioactivity in Agaricus campestris Mushroom Collected from Kahramanmaraș and Erzurum Proviences. Turkish Journal of Agriculture-Food Science and Technology 4(3): 208-215.

5. Sevindik M, Akgül H, Günal S, Doğan M (2016) Determination of antimicrobial activities and mineral contents of natural and culture forms of Pleurotus ostreatus. Kastamonu University Journal of Forestry 16(1): 153-156

6. Sevindik M (2018) Antioxidant and antimicrobial activity of Cerrena unicolor. Mycopath 16(1): 11-14
7. Sevindik M (2018) Heavy metals content and the role of Lepiota cristata as antioxidant in oxidative stress. J Bacteriol Mycol Open Access 6(4): 237-239.

8. Sevindik M, Akgul H, Bal C, Altuntas D, Korkmaz AI, et al. (2018) Oxidative Stress and Heavy Metal Levels of Pholiota limonella Mushroom Collected from Different Regions. Current Chemical Biology 12(2): 169-172.

9. Sevindik M (2019) The novel biological tests on various extracts of Cerioporus varius. Fresenius Environmental Bulletin 28(5): 3713-3717.

10. Sevindik M, Pehlivan M, Dogan M, Selamoglu Z (2018) Phenolic content and antioxidant potential of Terfezia boudieri. Gazi University Journal of Science 31(3): 707-711.

11. Thongwat D, Pimolsri U, Somboon P (2015) Screening for mosquito larvicidal activity of thai mushroom extracts with special reference to Steccherinum sp against Aedes aegypti (L) (Diptera: Culicidae). Southeast Asian J Trop Med Public Health 46(4): 586-595.

12. Gürgen A, Yıldız S, Çevik U, Çelik A (2019) Radionuclide Activity Concentrations of Agaricus bisporus and Pleurotus ostreatus Mushrooms Cultivated in Different Commercial Companies. Journal of International Environmental Application and Science 14(1): 13-20.

13. Ma L, Chen H, Dong P, Lu X (2013) Anti-inflammatory and anticancer activities of extracts and compounds from the mushroom Inonotus obliquus. Food Chem 139(1-4): 503-508.

14. Lovy A, Knowles B, Labbe R, Nolan L (2000) Activity of edible mushrooms against the growth of human T4 leukemic cancer cells, HeLa cervical cancer cells, and Plasmodium falciparum. Journal of herbs, spices \& medicinal plants 6(4): 49-57.

15. Elsayed EA, El Enshasy H, Wadaan MA, Aziz R (2014) Mushrooms: a potential natural source of anti-inflammatory compounds for medical applications. Mediators Inflamm 2014: 805841.

16. Asrafuzzaman M, Rahman MM, Mandal M, Marjuque M, Bhowmik A, Rokeya B, et al. (2018) Oyster mushroom functions as an antihyperglycaemic through phosphorylation of AMPK and increased expression of GLUT4 in type 2 diabetic model rats. Journal of Taibah University medical sciences 13(5): 465-471.

17. Lull C, Wichers HJ, Savelkoul HF (2005) Antiinflammatory and immunomodulating properties of fungal metabolites. Mediators Inflamm (2): 63-80.

18. Saga T, Yamaguchi K (2009) History of antimicrobial agents and resistant bacteria. JMAJ 52(2): 103-108.

19. Sevindik M, Akgul H, Dogan M, Akata I, Selamoglu Z (2018) Determination of antioxidant, antimicrobial, DNA protective activity and heavy metals content of Laetiporus sulphureus. Fresenius Environmental Bulletin 27(3): 1946-1952.

20. Sevindik M, Rasul A, Hussain G, Anwar H, Zahoor MK, Sarfraz I, et al. (2018) Determination of anti-oxidative, anti-microbial activity and heavy metal contents of Leucoagaricus leucothites. Pak J Pharm Sci 31(5 (Supplementary)): 2163-2168.

21. Sevindik M (2018) Investigation of Antioxidant/Oxidant Status and Antimicrobial Activities of Lentinus tigrinus. Adv Pharmacol Sci 2018: 1718025.

22. Celal B (2019) Antioxidant and antimicrobial capacities of Ganoderma lucidum. J Bacteriol Mycol Open Access 7(1): 5-7.

23. Kosanić M, Ranković B, Dašić M (2012) Mushrooms as possible antioxidant and antimicrobial agents. Iran J Pharm Res 11(4): 10951102.

24. Ramesh CH, Pattar MG (2010) Antimicrobial properties, antioxidant activity and bioactive compounds from six wild edible mushrooms of western ghats of Karnataka, India. Pharmacognosy Res 2(2): 107-112.

25. Gbolagade JS, Fasidi IO (2005) Antimicrobial activities of some selected Nigerian mushrooms. African Journal of Biomedical Research 8(2): 8387.

26. Sivakumar R, Vetrichelvan T, Rajendran NN, Devi MI, Sundaramoorthi K, et al. (2006) Antibacterial activity of mushroom Osmoporus odoratus. Indian journal of pharmaceutical sciences 68(4): 523-524. 
27. Yilmaz A, Yildiz S, Tabbouche S, Kılıç AO, Can Z (2016) Total phenolic content, antioxidant and antimicrobial properties of Pleurotus ostreatus grown on lime (Tilia Tomentosa) leaves. Hacettepe Journal of Biology and Chemistry 44(2): 119-124. 